\title{
Microbiota and age-related macular degeneration: where are we today?
}

\author{
Angelo Maria Minnella ${ }^{1,2}$, Francesca Albanesi ${ }^{1}$, Martina Maceroni ${ }^{1,2}$ \\ ${ }^{1}$ Università Cattolica del Sacro Cuore, Rome - Italy \\ ${ }^{2}$ UOC Oculistica, Fondazione Policlinico Universitario A. Gemelli - IRCCS, Rome - Italy
}

\begin{abstract}
Age-related macular degeneration (AMD) is a complex degenerative multifactorial retinal disease, representing a leading cause of legal blindness among elderly individuals. It is well known that age, family history, smoking, nutrition, and inflammation contribute to the development of AMD. Recent studies support the existence of a gut-retina axis involved in the pathogenesis of several ocular diseases, including AMD. High-fat and high simple sugar diets determine a derangement of the gut microbiota, with an increase of gut permeability and systemic low-grade inflammation. Leaky gut is correlated with higher levels of circulating microbial-associated pattern molecules, which trigger the systemic release of potent proinflammatory mediators and stimulate the specific immune cells of the retina, contributing to retinal damage. All these findings suggest that microbiota is closely related to AMD and that it may be targeted in order to influence AMD pathogenesis and/or its clinical course.
\end{abstract}

Keywords: Age-related macular degeneration, Gut-retina axis, Leaky gut, Microbiota, Micronutrients, Personalized medicine

Age-related macular degeneration (AMD) is a complex degenerative multifactorial retinal disease affecting photoreceptors and retinal pigment epithelium (RPE) (1).

AMD represents a leading cause of legal blindness among elderly individuals in the industrialized nations, with a global prevalence of $8.69 \%$ (4.26\%-17.40\%) (2). Sixty-seven million people are affected in Europe, whereas in Asian countries the prevalence is lower (3).

The prevalence of AMD increases with age among all ethnicities and in all geographic regions, contributing to the increase in AMD cases as a result of a growing aging population (Fig. 1). By 2021, we can calculate that the worldwide number of individuals with AMD is expected to reach 196 million; the number is expected to continue increasing, reaching 288 million cases by 2040 .

Central vision is key to many daily activities, including a person's ability to read, drive, and recognize faces. Consequently, the loss of central vision that accompanies AMD pathology greatly affects an individual's quality of life.

Received: February 5, 2021

Accepted: March 15, 2021

Published online: April 7, 2021

\section{Corresponding author}

Francesca Albanesi

Università Cattolica del Sacro Cuore

Largo Francesco Vito 1

00168 Roma RM - Italy

francesca.alba.96@gmail.com
Patients with AMD-associated vision loss have reported experiencing greater emotional distress or depressive disorder than non-visually impaired individuals, because they must rely on others to help them with tasks they previously handled independently.

Currently, the neovascular form (Fig. 2) may be able to be treated with the use of anti-vascular endothelial growth factor (VEGF) drugs, while no effective treatments are available for the dry form (Fig. 3).

Several risk factors have been linked to AMD, such as age, lifestyle (smoking and diet), and family history. Although the etiology of AMD is multifactorial, diet and nutrition have strong epidemiologic associations with disease onset and progression.

Although the precise causes of AMD remain unknown, there is a clear role of inflammation in the pathophysiology of this disease. The initial hypothesis that antioxidant dietary and nutritional factors could influence AMD (4) was based on the known influence of daily insults of free radical formation and oxidation, and that the retina was a set-up for these oxidative processes due to the abundance of polyunsaturated fatty acids (PUFAs) in the photoreceptor outer segment membranes. Thus, it was thought that dietary antioxidants could potentially block the damaging effect of oxidation and scavenge, decompose, or reduce the formation of these harmful compounds in the macula (5).

Diet is an excellent source of antioxidants, vitamins, and minerals necessary for healthy living and a wide variety of nutrients, such as minerals, vitamins, omega-3 (n-3) fatty acids, and various carotenoids, have been associated 

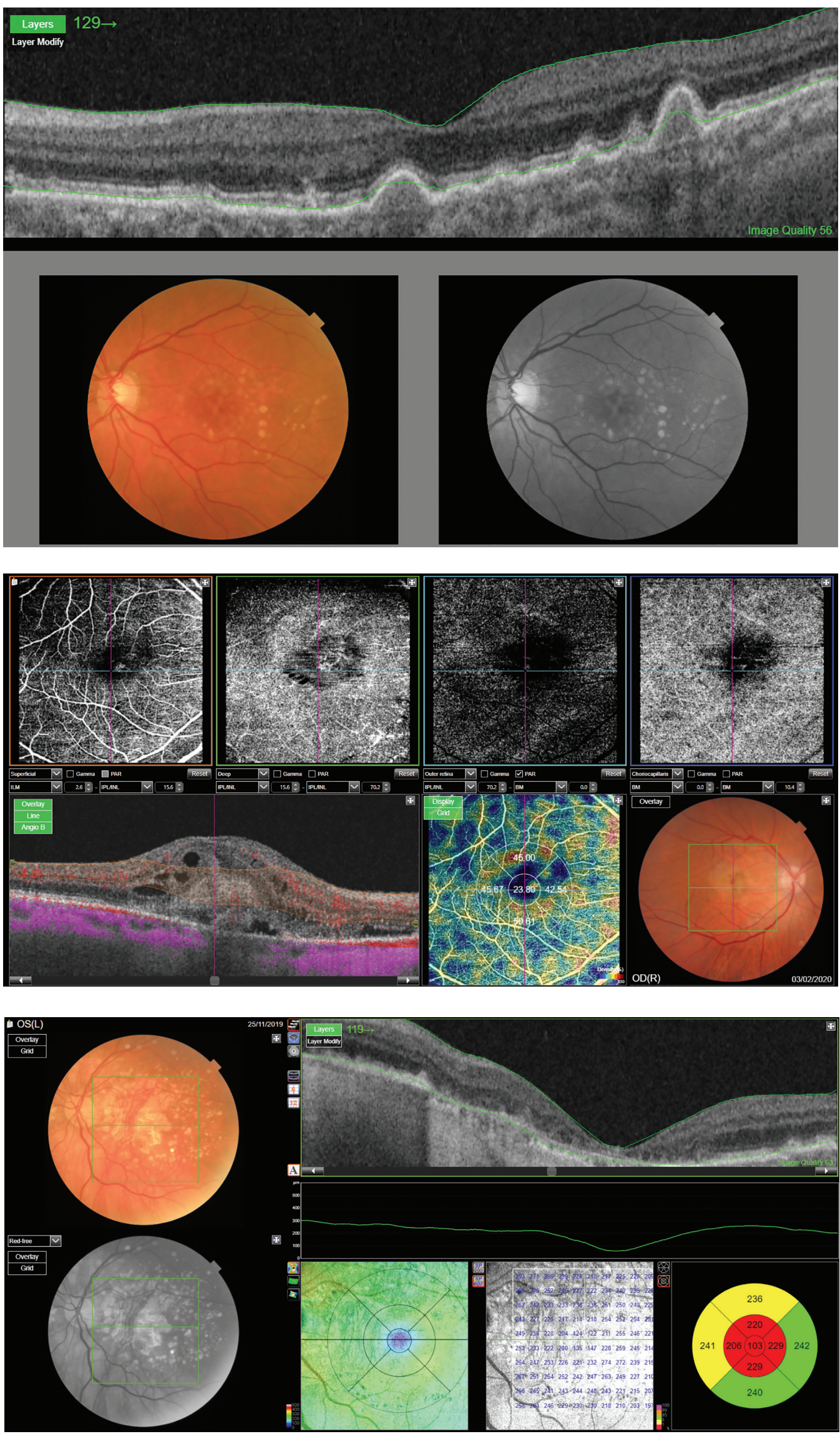

Fig. 1 - Age-related macular degeneration.

Color photograph and optical coherence tomography of an intermediate AMD.

Fig. 2 - Wet form of age-related macular degeneration.

Angio-optical coherence tomography shows presence of a macular neovascular complex, associated with multiple intraretinal cysts.

Fig. 3 - Dry form (geographic atrophy) of age-related macular degeneration.

Optical coherence tomography reveals reduction of external retinal layers associated with retinal pigment epithelium atrophy and backscattering of the signal. 
with reducing the risk of AMD in population-based studies. Nutritional supplements containing antioxidants, minerals, and essential fatty acids can be consumed as an alternative source.

The most important longitudinal studies to prove the effectiveness of vitamins and micronutrients in preventing the worsening of AMD remain the Age-Related Eye Disease Study (AREDS and AREDS2), which were both sponsored by the National Institutes of Health $(\mathrm{NIH})(6,7)$.

The studies showed the effectiveness of micronutrient supplementation in reducing the risk of disease progression. In particular, in the AREDS study report 8 of 2001, it was shown that the intake of high-dose antioxidants (vitamin $\mathrm{C}$, vitamin $\mathrm{E}$, beta-carotene), zinc, and cupric oxide significantly decreases the risk of progression from intermediate to late stages of the disease. A second study, the 2013 AREDS2, evaluated the role of increased intake of different carotenoids (lutein and zeaxanthin, the major components of macular pigment) as well as two specific omega-3 long-chain PUFAs (docosahexaenoic acid [DHA] + eicosapentaenoic acid [EPA]). The addition of lutein + zeaxanthin, DHA + EPA, or both to the original AREDS formulation did not further reduce the risk of progression to advanced AMD but was found to be equally effective. However, the use of lutein and zeaxanthin is definitely recommended in smoking patients instead of beta-carotene, as the latter increases the risk of lung cancer in patients at risk such as smokers and are generally more suitable to replace beta-carotene in each patient (8).

In addition, consumption of green leafy vegetables is recommended if approved by primary care physician (intake of vitamin $\mathrm{K}$ decreases effectiveness of warfarin) and fish/fish oils containing high levels of omega- 3 fatty acids.

Chiu et al (9) analyzed the eating habits of the patients included in the AREDS study, confirming that Western lifestyle tends to be more associated with AMD. In fact, a body mass index (BMI) greater than 25 is proportionally associated with the risk of AMD. Therefore, obesity and overweight are associated with an increased risk of AMD in a dose-dependent fashion, while a reduction in the waist-to-hip ratio has been demonstrated to decrease the risk of $\operatorname{AMD}(10,11)$.

There is a common denominator that connects aging, diet, and obesity, and this is the gut microbiota. Recent studies indicate a role for gut microbiota in the development of AMD in mouse models and in some forms of human AMD (12).

Each healthy individual has a common set of coevolved gut colonizers (the core gut microbiota) that help us in degrading otherwise indigestible food constituents (13). The gut microbiota is a complex ecosystem that colonizes the gastrointestinal tract, composed of Bacteria, Archaea, Fungi, and Viruses (14). There are thousands of bacterial species, but the most represented belong to a few Phyla: Firmicutes, Bacteroidetes, Actinobacteria, Proteobacteria, Verrucomicrobia, and Fusobacteria $(15,16)$. The composition of gut microbiota varies with dietary habits and geographical origins (17). The dominant microbiota species in the gut belong to the Bacteroidetes (mainly Gram-negative), and Firmicutes (mainly Gram-positive) divisions, and the presence of food leads to an enrichment of the Firmicutes species that increase the efficiency of intestinal fat absorption (18).
Likewise, the proportion of Firmicutes is significantly higher in obese humans and mice $(15,19)$. These bacteria seem to help their host to get more calories from ingested food that will be used as energy. In fact, Turnbaugh et al showed, in a mouse model, that this "obesity-associated gut microbiome" had an increased capacity to harvest energy from the diet, breaking down otherwise indigestible dietary polysaccharides. This phenotypic trait is transmissible as normal mice colonized with microbiota harvested from obese animals ("obese microbiota") have a higher abundance of Firmicutes and significantly gain more weight compared to animals that received a "lean microbiota" (15). This implies that the gut microbiota changes rapidly upon dietary intervention and that the obesity-associated gut microbiome primes the host for energy storage. A healthy diet and physiological microbiota are the basis of a balanced host-microbiota interaction that regulates intestinal and systemic immune homeostasis. Other forms of inadequate nutrition may occur during aging, and the microbiota of older people differ significantly from that of younger adults; such a loss of microbiota diversity is regarded as a biomarker of biological aging (20). These findings confirm the pivotal role of the gut microbiota in driving the metabolic pathways of obesity and low-grade inflammation.

High-glucose and fructose diets affect the whole pathophysiological system. Several studies (21) suggest that highcarbohydrate intake directly influences the microbiota, leading to a consequent increase of the intestinal permeability of at least 2.5 times (22). Rowan et al (23) studied mouse models in order to identify consequences of hyperglycemic diet on the retina. Hyperglycemic diet was associated with hypopigmentation of RPE and RPE atrophy, accumulation of lipofuscin, and degeneration of photoreceptors. The switch to a hypoglycemic diet stopped retinal degeneration, leading to an increase of the circulating protective metabolites (e.g., serotonin). The different diets were associated with different microbiota composition: increase in Clostridiales for the hyperglycemic diet, increase in Bacteroidales for hypoglycemic diet. These findings underline the importance of diet and lifestyle in patients with AMD.

Alterations in the composition of the gut microbiota, also termed dysbiosis, markedly affect the intestinal epithelial barrier and challenge the host immune system (24). Gut microbiota influence the pathogenesis of many diseases, as it can determine an increasing of the intestinal permeability (leaky gut), which allows the translocation of bacterial products and toxic substances in the blood. Thus, bacterial products such as the endotoxin lipopolysaccharides (LPS) and pathogenassociated molecular pattern molecules (PAMPs) are translocated into the blood flow, inducing low-grade inflammation in several tissues through the activation of pattern recognition receptors (PRRs); in addition, the metabolites produced by gut microbiota can stimulate the specific immune cells of the retina. Andriessen et al (12), using mouse models for microbiota manipulations, found that microbiota of obese subjects are related to choroidal neovascularization.

A study (25) conducted on 12 patients with advanced neovascular AMD demonstrated the recurrence of some alterations in the microbiota of the subjects in the study: an increasing of the bacterial genera Anaerotruncus, 
Oscillibacter, Ruminococcus torques, and Eubacterium ventriosum was noted, as well as an upregulation of the genes and pathways related to L-alanine fermentation, degradation of glutamate, and biosynthesis of arginine. Conversely, the activity of genes involved in the elongation of fatty acids was decreased. Another study links the long-term intake of Lactobacillus paracasei KW3110 to the prevention of chronic inflammation and retinal cell loss in aged mice (26).

Another role of gut microbiota is to regulate the absorption of micro- and macronutrients, including those related to AMD. The nutrients taken with the diet act directly as antioxidants and anti-inflammatory agents, and indirectly by modulating the intestinal microbiota. Therefore, the gut microbiota have a complex interaction with the macro- and micronutrients, many of which have been studied in AREDS and AREDS2.

The role of vitamin D has been recently studied (27). Vitamin D presents anti-inflammatory effect, protecting from reactive oxygen species (ROS), inhibiting beta-amyloid deposition, suppressing cytokines, inhibiting angiogenesis and metalloproteases. There are no randomized experimental studies on vitamin D supplementation in patients with AMD, but a protective role has been hypothesized. Furthermore, vitamin $D$ protects the integrity of the intestinal barrier and regulates immunity at the intestinal level. Vitamin D deficiency has been related to the relapse of inflammatory bowel disease (IBD) (28-30).

Studies $(31,32)$ have shown that levels of EPA and DHA in the cell membranes are reduced in AMD patients. Recent studies (33) suggested that the PUFAs, in association with microbiota and immune cells, are crucial to maintaining the homeostasis and the integrity of the intestinal wall. In addition, PUFAs influence the composition of the microbiota. Fish oil, which contains PUFAs, has shown to promote protective and anti-inflammatory species such as Bacteroides, Lactobacillus, and Akkermansia muciniphila in mouse models $(34,35)$.

Recent studies showed how-in fishes-molecules such as astaxanthin, obtained through diet, regulate gastrointestinal immunity and microbiota and retinal mitochondrial dysfunction under hypoxia conditions: high levels of astaxanthin result in a decline in Lactobacillus and Pseudomonas abundance, an increase in Vibrio abundance, and an arousal in oxidative stress and retinal apoptosis (36).

Moreover, another molecule providing this example is perfluorobutane sulfonate-an emerging aquatic pollutant that has been shown to be modulating both gut microbiota and retinoid metabolism in the eye (37).

As previously mentioned, the gut microbiota plays a fundamental role in the maintenance of the intestinal barrier and intestinal homeostasis (38). Gut permeability is measurable and could become a new target for the prevention and treatment of several diseases (39). A proinflammatory intestinal environment attracts immune system cells; calprotectin is a calcium- and zinc-binding protein mainly contained in neutrophils. Calprotectin is then released by neutrophils after they migrate into the gastrointestinal tissues. Fecal calprotectin is commonly used as a marker of inflammation in intestinal inflammatory pathologies, and its local increase is correlated with increased intestinal permeability and transepithelial migration of neutrophils (40).
Immunohistochemical tests (41) showed that patients with AMD present a greater amount of circulating self-reactive autoantibodies against calgranulin $B$, one of the two components of calprotectin. This protein is able to induce both apoptosis and autophagy, and it contributes to the development of AMD through these mechanisms.

The connection between eye and gut microenvironment can be held by further mechanisms, as the bile acids, recently demonstrated to be neuroprotective therapies in retinal disease (42).

This connection between bowel and eye is related not only to AMD but also to other retinal pathologies: the role of the commensal microflora in the induction of T cells linked to glaucoma neurodegeneration is another example that has been studied (43). Moreover, an altered gut microbiota can lead to the production of autoantibodies and autoreactive $T$ cells linked to primary open-angle glaucoma (44). Another recent study (45) has shown a strong connection between the process of remodeling gut microenvironment and the suppression of development of experimental autoimmune uveitis. Furthermore, there is a finding of response to nutritional therapies in diabetic retinopathy (46).

\section{Conclusions}

All this evidence supports the existence of a gut-retina axis involved in the pathogenesis of ocular diseases, mainly AMD. The biological crosstalk among diet, micronutrients, gut microbiota, and host immunity is a new frontier in the diagnosis and treatment of AMD.

Several studies support the evidence that high-fat and high simple sugar diets determine a derangement of the gut microbiota that leads to an increase of intestinal wall permeability and systemic low-grade inflammation. As a consequence, the metabolites produced by gut microbiota stimulate the specific immune cells of the retina, contributing to retinal damage. Further studies are needed to elucidate the complex interactions among the components of the gutretina axis. In conclusion, nutritional habits and micronutrient intake are able to influence AMD pathogenesis and/or its clinical course.

\section{Disclosures}

Conflict of interest: The authors declare no conflict of interest. Financial support: This research received no specific grant from any funding agency in the public, commercial, or not-for-profit sectors.

\section{References}

1. Li JQ, Welchowski T, Schmid M, Mauschitz MM, Holz FG, Finger RP. Prevalence and incidence of age-related macular degeneration in Europe: a systematic review and meta-analysis. Br J Ophthalmol. 2020;104(8):1077-1084. CrossRef PubMed

2. Pennington KL, DeAngelis MM. Epidemiology of age-related macular degeneration (AMD): associations with cardiovascular disease phenotypes and lipid factors. Eye Vis (Lond). 2016; 3(1):34. CrossRef PubMed

3. Wong WL, Su X, Li X, et al. Global prevalence of age-related macular degeneration and disease burden projection for 2020 
and 2040: a systematic review and meta-analysis. Lancet Glob Health. 2014;2(2):e106-e116. CrossRef PubMed

4. Rinninella E, Mele MC, Merendino N, et al. the role of diet, micronutrients and the gut microbiota in age-related macular degeneration: new perspectives from the gut-retina axis. Nutrients. 2018;10(11):1677. CrossRef PubMed

5. Sobrin L, Seddon JM. Nature and nurture-genes and environment-predict onset and progression of macular degeneration. Prog Retin Eye Res. 2014;40:1-15. CrossRef PubMed

6. Age-Related Eye Disease Study Research Group. A randomized, placebo-controlled, clinical trial of high-dose supplementation with vitamins $C$ and $E$, beta carotene, and zinc for age-related macular degeneration and vision loss: AREDS report no. 8. Arch Ophthalmol. 2001;119(10):1417-1436. CrossRef PubMed

7. Age-Related Eye Disease Study 2 Research Group. Lutein + zeaxanthin and omega-3 fatty acids for age-related macular degeneration: the Age-Related Eye Disease Study 2 (AREDS2) randomized clinical trial. JAMA. 2013;309(19):2005-2015. CrossRef PubMed

8. Chew EY, Clemons TE, Sangiovanni JP, et al; Age-Related Eye Disease Study 2 (AREDS2) Research Group. Secondary analyses of the effects of lutein/zeaxanthin on age-related macular degeneration progression: AREDS2 report No. 3. JAMA Ophthalmol. 2014;132(2):142-149. CrossRef PubMed

9. Chiu CJ, Taylor A. Dietary hyperglycemia, glycemic index and metabolic retinal diseases. Prog Retin Eye Res. 2011;30(1): 18-53. CrossRef PubMed

10. Zhang QY, Tie LJ, Wu SS, et al. Overweight, obesity, and risk of age-related macular degeneration. Invest Ophthalmol Vis Sci. 2016;57(3):1276-1283. CrossRef PubMed

11. Peeters A, Magliano DJ, Stevens J, Duncan BB, Klein R, Wong TY. Changes in abdominal obesity and age-related macular degeneration: the Atherosclerosis Risk in Communities Study. Arch Ophthalmol. 2008;126(11):1554-1560. CrossRef PubMed

12. Andriessen EM, Wilson AM, Mawambo G, et al. Gut microbiota influences pathological angiogenesis in obesity-driven choroidal neovascularization. EMBO Mol Med. 2016;8(12):1366-1379. CrossRef PubMed

13. Sender R, Fuchs S, Milo R. Are we really vastly outnumbered? Revisiting the ratio of bacterial to host cells in humans. Cell. 2016;164(3):337-340. CrossRef PubMed

14. Bäckhed F, Ley RE, Sonnenburg JL, Peterson DA, Gordon JI. Host-bacterial mutualism in the human intestine. Science. 2005;307(5717):1915-1920. CrossRef PubMed

15. Turnbaugh PJ, Ley RE, Mahowald MA, Magrini V, Mardis ER, Gordon JI. An obesity-associated gut microbiome with increased capacity for energy harvest. Nature. 2006;444(7122):10271031. CrossRef PubMed

16. Eckburg PB, Bik EM, Bernstein CN, et al. Diversity of the human intestinal microbial flora. Science. 2005;308(5728):1635-1638. CrossRef PubMed

17. Senghor B, Sokhna C, Ruimy R, Lagier JC. Gut microbiota diversity according to dietary habits and geographical provenance. Hum Microb J. 2018;7-8:1-9. CrossRef

18. Semova I, Carten JD, Stombaugh J, et al. Microbiota regulate intestinal absorption and metabolism of fatty acids in the zebrafish. Cell Host Microbe. 2012;12(3):277-288. CrossRef PubMed

19. Ley RE, Bäckhed F, Turnbaugh $P$, Lozupone $C A$, Knight RD, Gordon JI. Obesity alters gut microbial ecology. Proc Natl Acad Sci USA. 2005;102(31):11070-11075. CrossRef PubMed

20. O'Toole PW, Jeffery IB. Gut microbiota and aging. Science. 2015;350(6265):1214-1215. CrossRef PubMed

21. Schleicher M, Weikel K, Garber C, Taylor A. Diminishing risk for age-related macular degeneration with nutrition: a current view. Nutrients. 2013;5(7):2405-2456. CrossRef PubMed
22. Do MH, Lee E, Oh MJ, Kim Y, Park HY. High-glucose or -fructose diet cause changes of the gut microbiota and metabolic disorders in mice without body weight change. Nutrients. 2018; 10(6):761. CrossRef PubMed

23. Rowan $\mathrm{S}$, Jiang $\mathrm{S}$, Korem $\mathrm{T}$, et al. Involvement of a gut-retina axis in protection against dietary glycemia-induced agerelated macular degeneration. Proc Natl Acad Sci USA. 2017; 114(22):E4472-E4481. CrossRef PubMed

24. Cerf-Bensussan N, Gaboriau-Routhiau V. The immune system and the gut microbiota: friends or foes? Nat Rev Immunol. 2010;10(10):735-744. CrossRef PubMed

25. Zinkernagel MS, Zysset-Burri DC, Keller I, et al. Association of the intestinal microbiome with the development of neovascular age-related macular degeneration. Sci Rep. 2017;7(1):40826. CrossRef PubMed

26. Morita Y, Jounai K, Sakamoto A, et al. Long-term intake of Lactobacillus paracasei KW3110 prevents age-related chronic inflammation and retinal cell loss in physiologically aged mice. Aging (Albany NY). 2018;10(10):2723-2740. CrossRef PubMed

27. Layana AG, Minnella AM, Garhöfer G, et al. Vitamin D and agerelated macular degeneration. Nutrients. 2017;9(10):1120. CrossRef PubMed

28. Luthold RV, Fernandes GR, Franco-de-Moraes AC, Folchetti LG, Ferreira SR. Gut microbiota interactions with the immunomodulatory role of vitamin $D$ in normal individuals. Metabolism. 2017;69:76-86. CrossRef PubMed

29. Gubatan J, Moss AC. Vitamin D in inflammatory bowel disease: more than just a supplement. Curr Opin Gastroenterol. 2018; 34(4):217-225. CrossRef PubMed

30. Bashir M, Prietl B, Tauschmann M, et al. Effects of high doses of vitamin D3 on mucosa-associated gut microbiome vary between regions of the human gastrointestinal tract. Eur J Nutr. 2016;55(4):1479-1489. CrossRef PubMed

31. Souied EH, Delcourt C, Querques G, et al; Nutritional AMD Treatment 2 Study Group. Oral docosahexaenoic acid in the prevention of exudative age-related macular degeneration: the Nutritional AMD Treatment 2 study. Ophthalmology. 2013;120(8):1619-1631. CrossRef PubMed

32. SanGiovanni JP, Chew EY, Clemons TE, et al; Age-Related Eye Disease Study Research Group. The relationship of dietary lipid intake and age-related macular degeneration in a casecontrol study: AREDS Report No. 20. Arch Ophthalmol. 2007;125(5):671-679. CrossRef PubMed

33. Parolini C. Effects of fish n-3 PUFAs on intestinal microbiota and immune system. Mar Drugs. 2019;17(6):374. CrossRef PubMed

34. David LA, Maurice CF, Carmody RN, et al. Diet rapidly and reproducibly alters the human gut microbiome. Nature. 2014;505(7484):559-563. CrossRef PubMed

35. Robertson RC, Kaliannan K, Strain CR, Ross RP, Stanton C, Kang JX. Maternal omega-3 fatty acids regulate offspring obesity through persistent modulation of gut microbiota. Microbiome. 2018;6(1):95. CrossRef PubMed

36. Niu J, Zhao W, Lu DQ, et al. Dual-function analysis of astaxanthin on golden pompano (Trachinotus ovatus) and its role in the regulation of gastrointestinal immunity and retinal mitochondrial dysfunction under hypoxia conditions. Front Physiol. 2020;11:568462. CrossRef PubMed

37. Hu C, Tang L, Liu M, Lam PKS, Lam JCW, Chen L. Probiotic modulation of perfluorobutane sulfonate toxicity in zebrafish: disturbances in retinoid metabolism and visual physiology. Chemosphere. 2020;258:127409. CrossRef PubMed

38. $\mathrm{Mu} \mathrm{Q}$, Kirby J, Reilly $\mathrm{CM}$, Luo XM. Leaky gut as a danger signal for autoimmune diseases. Front Immunol. 2017;8:598. CrossRef PubMed 
39. Bischoff SC, Barbara G, Buurman W, et al. Intestinal permeability-a new target for disease prevention and therapy. BMC Gastroenterol. 2014;14(1):189. CrossRef PubMed

40. Berstad A, Arslan G, Folvik G; A. Berstad, G. Arslan, G. Folvik. Relationship between intestinal permeability and calprotectin concentration in gut lavage fluid. Scand J Gastroenterol. 2000;35(1):64-69. CrossRef PubMed

41. Iannaccone A, Giorgianni F, New DD, et al; Health ABC study. Circulating autoantibodies in age-related macular degeneration recognize human macular tissue antigens implicated in autophagy, immunomodulation, and protection from oxidative stress and apoptosis. PLoS One. 2015;10(12):e0145323. CrossRef PubMed

42. Daruich A, Picard E, Boatright JH, Behar-Cohen F. Review: the bile acids urso- and tauroursodeoxycholic acid as neuroprotective therapies in retinal disease. Mol Vis. 2019;25:610-624. PubMed
43. Tang J, Tang Y, Yi I, Chen DF. The role of commensal microflorainduced $\mathrm{T}$ cell responses in glaucoma neurodegeneration. Prog Brain Res. 2020;256(1):79-97. CrossRef PubMed

44. Chaiwiang N, Poyomtip T. Microbial dysbiosis and microbiotagut-retina axis: the lesson from brain neurodegenerative diseases to primary open-angle glaucoma pathogenesis of autoimmunity. Acta Microbiol Immunol Hung. 2019;66(4): 541-558. CrossRef PubMed

45. Zhou J, Yang J, Dai M, et al. A combination of inhibiting microglia activity and remodeling gut microenvironment suppresses the development and progression of experimental autoimmune uveitis. Biochem Pharmacol. 2020;180:114108. CrossRef PubMed

46. Shi $C$, Wang $P$, Airen $S$, et al. Nutritional and medical food therapies for diabetic retinopathy. Eye Vis (Lond). 2020;7(1):33. CrossRef PubMed 